\title{
The Use of Method of Loci (MoL) Teaching Tools Enhances Students' Short-Term Memory
}

Eddie Ti Tjih Tan (Corresponding author)

Alliance of Research and Innovation for Food (ARIF), Universiti Teknologi MARA, Cawangan Negeri Sembilan, Kampus Kuala Pilah, 72000 Kuala Pilah, Negeri Sembilan, Malaysia.

E-mail: eddietan@uitm.edu.my

Alice Shanthi

Academy of Language Studies, Universiti Teknologi MARA,

Cawangan Negeri Sembilan, Kampus Seremban, 73000 Seremban, Negeri Sembilan,

Malaysia.

E-mail: aliceshanthi@uitm.edu.my

\section{Nadya Hajar}

Alliance of Research and Innovation for Food (ARIF), Universiti Teknologi MARA, Cawangan Negeri Sembilan, Kampus Kuala Pilah, 72000 Kuala Pilah, Negeri Sembilan, Malaysia.

E-mail: nadya1844@uitm.edu.my

\section{Zuraida Jaafar}

Faculty of Computer and Mathematical Sciences, Universiti Teknologi MARA, Cawangan Negeri Sembilan, Kampus Kuala Pilah, 72000 Kuala Pilah, Negeri Sembilan, Malaysia.

E-mail: zuraida@uitm.edu.my 


\title{
Macrothink \\ International Journal of Social Science Research \\ ISSN 2327-5510 \\ 2022, Vol. 10, No. 1
}

Nurul Azlin Tokiman

Alliance of Research and Innovation for Food (ARIF), Universiti Teknologi MARA, Cawangan Negeri Sembilan, Kampus Kuala Pilah, 72000 Kuala Pilah, Negeri Sembilan, Malaysia.

E-mail: nurulazlin@uitm.edu.my

Nur Rabiatul Adawiah Mohammad Noor

Alliance of Research and Innovation for Food (ARIF), Universiti Teknologi MARA,

Cawangan Negeri Sembilan, Kampus Kuala Pilah, 72000 Kuala Pilah, Negeri Sembilan, Malaysia.

E-mail: rabiatuladawiah@uitm.edu.my

Received: Dec. 20, 2021 Accepted: Jan. 29, 2022 Published: Feb. 28, 2022

doi:10.5296/ijssr.v10i1.19341ＵRL: https://doi.org/10.5296/ijssr.v10i1.19341

\begin{abstract}
To recall Hazard Analysis Critical Control Points (HACCP) principles and implementation steps was challenging for Food Technology Program students, though remembering the principles and steps usually requires lower-order thinking skills. Previous reports indicated that using the Method of Loci (MoL) in teaching and learning (T\&L) has noticeable potential to enhance students' memory and further improve their learning capacity. Therefore, conventional lecture MoL (CLMoL) teaching tools were developed. This study aims to investigate the short-term and long-term memory retention among participants after using CLMoL teaching tools in T\&L of HACCP principles and implementation steps. In this experiment, two (2) groups of participants were taught using Conventional Lecture (CL), and the other two (2) groups were taught using CLMoL teaching tools. Thereafter, four (4) similar memory recall written assessments were performed, namely, pre-intervention assessment (Q1), post - intervention assessment (Q2), 4 - week follow - up assessment (Q3, 29 to 32 days), and final examination (FE). Q2 and Q3 assessments showed significantly better $(p \leq 0.05)$ short-term and long-term memory recall for the CLMoL group (treated group) compared to the CL group. Even though the Q3 mean score for the CLMoL group was still significantly higher than the CL group, the mean scores for both groups indicated a declining pattern after a lapse of a month. The assessment results, along with the positive survey responses suggest that the use of CLMoL teaching tools may improve the efficacy of T\&L of the HACCP concept by apparently enhancing the short-term memorization of the HACCP principles and steps of implementation.
\end{abstract}




\section{Macrothink}

International Journal of Social Science Research

ISSN 2327-5510

2022, Vol. 10, No. 1

Keywords: method of loci, long-term memory, short-term memory, learning, mnemotechnic 


\section{Introduction}

One of the fundamental concepts of knowledge for the Food Technology students in applying their knowledge on Hazard Analysis and Critical Control Points (HACCP) principles with its implementation steps to identify food safety risks and manage the food production system. This concept has seven (7) principles with twelve (12) steps of implementation (Mortimore \& Wallace, 2013). Hence, understanding and memorizing the principles and steps are likely beneficial to them when working in the food production establishments later, especially in controlling the quality of the food produces (Allata, Valero, \& Benhadja, 2017; Lu, Pua, Liu, Chang, \& Cheng, 2014; Rifqie Mariana, Hidayati, \& Soekopitojo, 2019).

Nevertheless, several personal communications with a large number of Food Technology students in the Universiti Teknologi MARA found out that they do not aware of the empirically proven mnemotechnics that can help in learning, therefore they were having difficulties in remembering the HACCP principles and steps of implementation. This finding also accords with earlier observations, which showed that many undergraduates may not verse in mnemotechnics such as Method of Loci (MoL) that could enhance their academic performance (Hartwig \& Dunlosky, 2012; McCabe, 2011, 2015).

The MoL, called Memory Palaces, is a mnemotechnic that uses familiar spaces to arrange, store, and recall memory (Dalgleish et al., 2013). The MoL in enhancing memory recall can be dated back to the Greek Era (Yates Frances, 1966) and interestingly, this ancient mnemotechnic is still being used to this day (Shaw \& Hosseini, 2020; Singzon, 2020; Vetter, Götz, \& von Mammen, 2020).

Numerous existing research and review works on the MoL recognize its role in memory enhancement (Kurniarahman, 2020; McCabe, 2018; Perrault, Lecolinet, Bourse, Zhao, \& Guiard, 2015; Vetter et al., 2020; Wilding \& Valentine, 1997). An extensive comparative study of MoL has demonstrated significant improvement in memory attainment across different age groups in various controlled human subjects (Brehmer, Li, Müller, von Oertzen, \& Lindenberger, 2007; McDaniel \& Bugg, 2012).

In addition, a vast number of MoL related studies have been conducted in education institutions. For instance, the use of the MoL in a college reported has induced students' memory with an incremental use of this mnemotechnic in their lives (McCabe, 2015). Another typical MoL application would be language and vocabulary learning (Bram, Sutono, \& Hermayani, 2020; Kurniarahman, 2020; Rawendy, Ying, Arifin, \& Rosalin, 2017). The method has also successfully helped the students memorize economics-related information (Shaughnessy \& White, 2012). All these reports suggest a great potential for this method to be applied in higher education for students to retain more new concepts and information (Huttner, Qian, \& Robra-Bissantz, 2019).

In consideration of the suggestion mentioned above for using $\mathrm{MoL}$ as an effective mnemotechnic to recall short-term and long-term memory, conventional lecture with the use of MoL $(\mathrm{CLMoL})$ teaching tools were developed to aid the T\&L. The teaching tools consist of virtual illustration and description statements to facilitate the conventional lecture session 
on HACCP principles and steps of implementation. Even though several authors have considered the positive short-term memory recall effects after the use of MoL in building up memorization of non-spatial information, there are several reports challenged the effectiveness of the MoL in learning (Brehmer et al., 2008; De Beni \& Cornoldi, 1988; Massen \& Vaterrodt-Plünnecke, 2006).

Since, the impact of the newly developed CLMoL teaching tools has not yet been studied, this paper aims to investigate the effectiveness for the use of the teaching tool. The current study was conducted in the form of written assessments over a period of time, survey, and interview sessions. The data presented in this paper provide indicators on the effectiveness for the use of the teaching tools in enhancing the short-term and long-term memory of the participants, based on the recollection of the principles of HACCP and its steps of implementation.

\section{Methods}

\subsection{Design and Participants}

Participants for this experiment were students ( $n=81 ; 11$ males; ages $20-22$ years) of diploma in Food Technology Program (session 1 2019/2020) at the Universiti Teknologi MARA (UiTM), Kuala Pilah Campus. During the enrolment, experimental subjects were randomly divided into four (4) groups, and consents were obtained before experimentation. Two (2) groups were randomly selected again and subjected to CL only (controlled), while the other two (2) groups were subjected to CLMoL (treated). None of the participants in the CLMoL treated group had any experience with the MoL before the experiment. All analyses were performed by combining the data obtained from the two (2) groups for each learning method (CL and CLMoL). Though the study started with 81 participants, only 75 participants completed all 4 phases of the experimental sessions, namely, Quiz 1 (Q1), Quiz 2 (Q2), Quiz (Q3), and Final Examination (FE). Therefore, the final analysis only included data from the 75 participants. The consent of this human subjects' experimentation study was obtained under the Research Management Unit (RMU) and endorsed by the Chair of the Research Committee of UiTM Cawangan Negeri Sembilan (Reference No. RMC-PTB 1/2019).

\subsection{Materials and Measures}

This experiment was designed to evaluate the participants' short-term and long-term memory retention after learning the principles and steps of HACCP implementation. A visual illustration (Figure 1) was developed to assist the participants in visualizing standard lecture rooms in order to enhance the recall of the HACCP concept. The visual illustration was sent to each participant in CLMoL groups (treated) via WhatsApp after the Conventional Lecture (CL). 


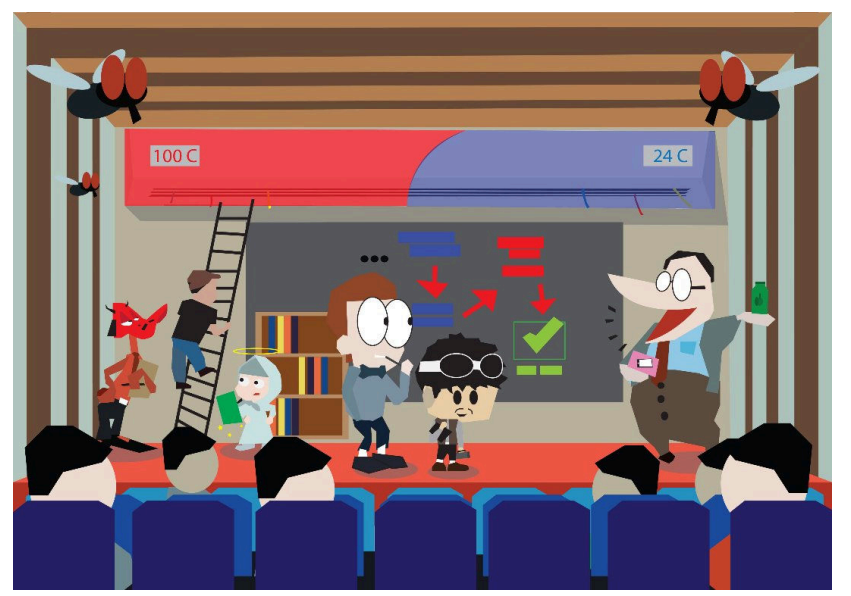

Figure 1. The visual illustration of the CLMoL teaching tool (Tan, 2021)

Afterwards, the visual illustration (Figure 1) was described and explained verbally by the facilitator with the aid of the description for the visual illustration (Figure 2). The above-mentioned striking characters and figures in the visual illustration, and the description tools link the principles and steps of HACCP implementation to the spatial syntax of the lecture room.

\section{HACCP PLAN short story}

Instruction: The facilitator has to read the short story below with the aid of the developed graphical illustration

\begin{tabular}{|c|c|c|c|c|}
\hline & No. & Description & $\begin{array}{l}\text { Steps } / \\
\text { Principles }\end{array}$ & Developing a HACCP Plan \\
\hline \multirow{5}{*}{$\begin{array}{l}\text { Preliminary } \\
\text { steps }\end{array}$} & 1 & Look at a group of lecturers standing in front of the class. & Step 1 & Assemble HACCP team \\
\hline & 2 & $\begin{array}{l}\text { The lecturer with a wide mouth gives explanation about a product he is holding in } \\
\text { his hand. }\end{array}$ & Step 2 & Describe the product \\
\hline & 3 & $\begin{array}{l}\text { Another lecturer with big eyes looks at the product to identify the intended used of } \\
\text { the product. }\end{array}$ & Step 3 & Identify the intended used \\
\hline & 4 & A flow diagram is available on the board. & Step 4 & Construct the flow diagram \\
\hline & 5 & A big green tick on the board means verifying the flow diagram. & Step 5 & Verify the flow diagram on site \\
\hline \multirow[t]{7}{*}{$\begin{array}{l}\text { Principles of } \\
\text { HACCP }\end{array}$} & 6 & $\begin{array}{l}\text { Look at the big flies (hazard) in the room. Look at the red big air conditioner, the } \\
\text { temperature is } 100^{\circ} \mathrm{C} \text { (hazard). Both hazards will disturb teaching and learning } \\
\text { process in the room. Which one is more critical, the big flies or the red big air } \\
\text { conditioner? Conduct a hazard analysis to determine your answer. }\end{array}$ & $\begin{array}{l}\text { Step } 6 \\
\text { Principle } 1\end{array}$ & Conduct hazard analysis \\
\hline & 7 & $\begin{array}{l}\text { We determined the high air conditioner temperature setting is more critical than the } \\
\text { big flies in the room. }\end{array}$ & $\begin{array}{l}\text { Step } 7 \\
\text { Principle } 2\end{array}$ & $\begin{array}{l}\text { Determine the critical control } \\
\text { point (CCP) }\end{array}$ \\
\hline & 8 & $\begin{array}{l}\text { A temperature of } 24^{\circ} \mathrm{C} \text { is the maximum limit for comfortable learning environment. } \\
\text { Look at the blue light on the air conditioner. }\end{array}$ & $\begin{array}{l}\text { Step } 8 \\
\text { Principle } 3\end{array}$ & $\begin{array}{l}\text { Establish critical limits for each } \\
\text { CCP }\end{array}$ \\
\hline & 9 & $\begin{array}{l}\text { The devil beside the staircase is monitoring a human climbing the staircase and } \\
\text { hoping the human is not going to fix the temperature. }\end{array}$ & $\begin{array}{l}\text { Step } 9 \\
\text { Principle } 4\end{array}$ & $\begin{array}{l}\text { Establish a monitoring } \\
\text { procedure for each CCP }\end{array}$ \\
\hline & 10 & $\begin{array}{l}\text { The human who is climbing the staircase is trying to fix the temperature of the air } \\
\text { conditioner from a red light that indicates } 100^{\circ} \mathrm{C} \text { to a blue temperature of } 24^{\circ} \mathrm{C} \text {. }\end{array}$ & $\begin{array}{l}\text { Step } 10 \\
\text { Principle } 5\end{array}$ & Establish corrective action plan \\
\hline & 11 & $\begin{array}{l}\text { The angel standing on the other side of the staircase is verifying the good deed } \\
\text { that the human is doing the correcting the temperature of the air conditioner. }\end{array}$ & $\begin{array}{l}\text { Step } 11 \\
\text { Principle } 6\end{array}$ & $\begin{array}{l}\text { Establish the verification } \\
\text { procedures }\end{array}$ \\
\hline & 12 & A big shelf beside the angel is meant for record keeping of the human's deeds. & $\begin{array}{l}\text { Step } 12 \\
\text { Principle } 7\end{array}$ & $\begin{array}{l}\text { Establish the documentation and } \\
\text { record keeping procedure }\end{array}$ \\
\hline
\end{tabular}

Figure 2. The description for the visual illustration (Figure 1) of the CLMoL teaching tool (Tan, 2021) 


\subsection{Assessments}

Three (3) assessments, Quiz 1 (Q1), Quiz 2 (Q2), and Quiz 3 (Q3) was composed of subjective questions. The authors used a pre-assessment (Q1), post - assessment (Q2), and after a 4 - week follow - up assessment (Q3, 29 to 32 days). These assessments were used to examine participants' memory recall for the principles and steps of HACCP implementation toward the learning approaches (CL (controlled) and CLMoL (treated)). All the questions for the assessments (Q1, Q2, and Q3) and the answer schemes were the same. The participants' final examination (FE) answer scripts were reassessed according to the same answer schemes for the quizzes without checking on the elaborative statements for each HACCP principle and step. This was done so that the memory assessment of the HACCP principles and steps could be standardized for all the assessments. Each assessment has a total score of nineteen per cent $(19 \%)$, and the results of the quizzes were used to compare the short-term and long-term effectiveness of CLMoL in memory retention.

\subsection{Questionnaires}

Eight (8) Likert-scale questions (Table 1) in the questionnaires were distributed to the former students $(n=29)$ (session 2 2018/2019) who have learned about the principles and steps of HACCP implementation through CLMoL teaching tools. This set of questionnaires was used to analyze the perception of CLMoL teaching tools in T\&L, the HACCP principles, and implementation steps. The reliability of the questionnaires was assessed. The reliability of the questionnaire and the scale were validated before the survey was conducted. The Cronbach's Alpha coefficient for the pilot study was 0.87 , which indicates the questionnaire is reliable $(\alpha>0.6)$ to be employed for research (Sekaran \& Bougie, 2016). Subsequently, the validated questionnaires were distributed immediately to all the participants of CLMoL after the Q2 and Q3 assessments via Google Form. However, only the responses of those who had taken all four (4) assessments from the treated group were analyzed $(n=37)$. Written volunteer consent was obtained from each participant before answering the questions.

Table 1. List of questions to gauge participants' perception of CLMoL teaching tools

\begin{tabular}{ll}
\hline Question & Item \\
\hline Que1 & I was able to learn the 7 principles and 12 steps of HACCP plan better after learning them with \\
& MoL. \\
Que2 & MoL is a helpful learning technique in memorizing facts. \\
Que3 & MoL helped me to understand the 7 principles and 12 steps in HACCP better. \\
Que4 & I learn better using MoL compared to the traditional way where teacher plainly explains. \\
Que5 & I would like to continue using MoL to learn more topics and subjects. \\
Que6 & I believe I will perform better on my assessments on topics that I learned using MoL. \\
Que7 & I would like to share the MoL technique with friends and family. \\
Que8 & Learning using MoL reduces the stress and anxiety to memorize 7 principles and 12 steps to \\
& develop a HACCP plan.
\end{tabular}




\subsection{Interview}

Five (5) participants from each CLMoL treated group were randomly selected for a short interview immediately after the Q3 to address their learning experience using CLMoL teaching tools. The interview sessions were also conducted to identify the strength and weaknesses of CLMoL teaching tools in T\&L, the principles, and the implementation steps of HACCP.

\subsection{Statistical Analysis}

The data were analyzed by using Statistical Package for Social Sciences (SPSS). Descriptive statistics, such as mean, standard deviation, and percentage of participants who agree on the CLMoL teaching tools was calculated. The independent sample t-test was done by comparing the mean score differences between the CLMoL intervention (treated group) and CL alone (controlled group) to assess the memorizing ability of the participants on the principles and steps of HACCP implementation. Paired sample t-tests were also carried out to determine the effectiveness of CLMoL teaching tools in helping the participants recall the principles and steps. All p-values in this study were performed at a significance level of 0.05 . If the p-value is less than or equal to 0.05 ( $p \leq 0.05$ ), it indicates a significant difference between the mean of the groups tested.

\section{Results and Discussion}

The first set of analyses examined the Cumulative Grade Point Average (CGPA) of the participants. The participants were tested for baseline performance. Table 2 shows that there is no significant difference ( $p>0.05$ ) for the CGPA mean of the CL participants $(3.307 \pm 0.430$ (Mean \pm SD), 2.280 (Min), $3.970(\mathrm{Max}))$ and the CLMoL participants $(3.454 \pm 0.371$ (Mean \pm SD), 2.390 (Min), 3.880 (Max)). This indicates that the academic performance for both groups (controlled and treated) of participants is indistinguishable from the CGPA.

Table 2. The mean cumulative grade point average (CGPA) of the CL participants and the CLMoL participants

\begin{tabular}{|c|c|c|c|}
\hline \multicolumn{4}{|c|}{ Cumulative Grade Point Average (CGPA) } \\
\hline Group & Mean & SD & p-value \\
\hline $\mathrm{CL}(n=38)$ & 3.307 & 0.430 & $p>0.05$ \\
\hline CLMoL $(n=37)$ & 3.454 & 0.371 & \\
\hline
\end{tabular}

Of the study population ( $n=81), 93 \%$ of the subjects $(n=75)$ completed all four assessments (Q1, Q2, Q3, and FE). One of the ways to assess the effectiveness of the use of CLMoL teaching tools was by comparing the mean scores between the participants who were taught by using CLMoL (treated group) and the participants who were taught by the CL alone (controlled group). In general, the CLMoL group performed better in all assessments than the 
participants taught by using CL alone (Figure 3).

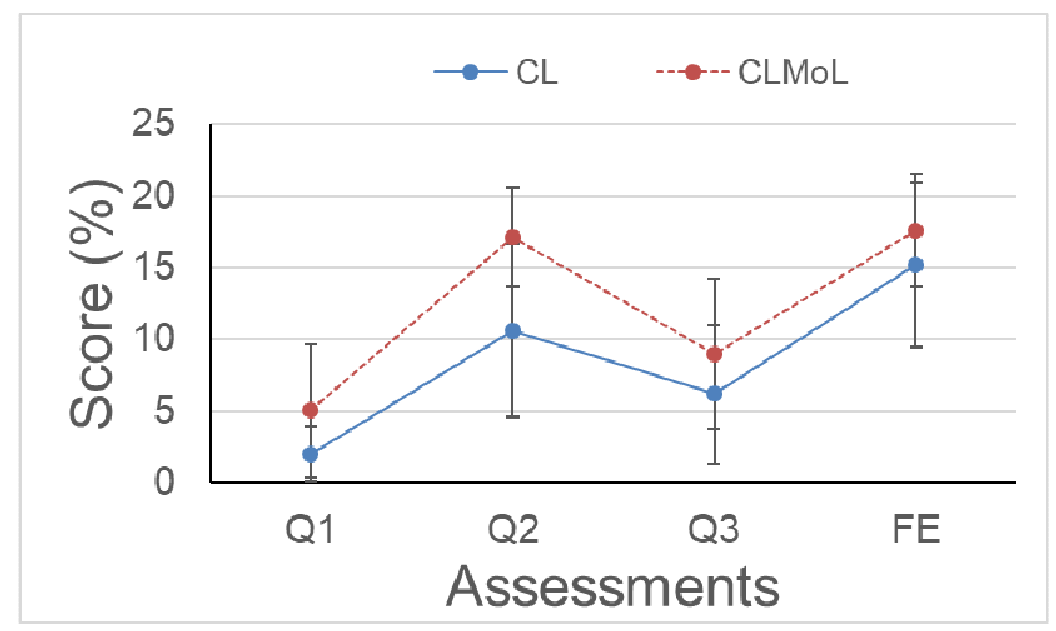

Figure 3. Mean scores for the assessments (Quiz 1 (Q1), Quiz 2 (Q2), Quiz 3 (Q3), and final exam (FE)) after T\&L (CLMoL and CL)

Table 3 compares the mean scores of all the assessments for the participants before and after T\&L (CLMoL and CL). Q1 was given to the participants before the learning process, and Q2 was given immediately after the learning process, while Q3 was given after approximately a month for each group of participants.

The Independent sample t-tests in Table 3 show that the mean scores of Q2, Q3, and FE for the treated group taught with CLMoL teaching tools are higher than the controlled group taught with CL only, and these differences are significant $(p \leq 0.05)$. These observations demonstrated better efficacy of CLMoL teaching tools than the CL in T\&L the principles and steps of HACCP implementation.

Table 3. Mean scores of the assessments (Q1, Q2, Q3, and Q4) after T\&L (CLMoL and CL)

\begin{tabular}{llllll}
\hline Assessment & Groups & $\boldsymbol{n}$ & Mean Score (\%) & SD & p-value \\
\hline Quiz 1 (Q1) & CLMoL & 37 & 5.054 & 4.654 & $p \leq 0.05$ \\
& & & & & \\
& CL & 38 & 2.053 & 1.902 & \\
Quiz 2 (Q2) & CLMoL & 37 & 17.135 & 3.449 & $p \leq 0.05$ \\
& & & & & \\
Quiz 3 (Q3) & CL & 38 & 10.632 & 6.011 & \\
& CLMoL & 37 & 9.000 & 5.228 & $p \leq 0.05$ \\
& & & & & \\
Final (FE) & CL & 38 & 6.211 & 4.816 & \\
& CLMoL & 37 & 17.568 & 3.927 & $p \leq 0.05$ \\
\hline
\end{tabular}


Nevertheless, it could be argued that the positive results were due to a significantly higher pre-assessment mean score (Q1) obtained by the CLMoL group, even though the academic performance (based on CGPA) of the treated and nontreated groups were nearly equal (Table 2 ). This observation indicates that some of the participants in the CLMoL group may have preconceived knowledge of the HACCP before the T\&L session via self-learning before the learning session, and this assumption was further ratified during the interview session.

Even so, the mean scores and the standard deviation data (Table 3) show that the short-term memory (Q2 mean score) for the CLMoL treated group increased 12.1 points from $5.1 \%$ to $17.1 \%$ with a low standard deviation (3.5\%). Notwithstanding the CL group, the Q2 mean score only raised 8.6 points from $2.1 \%$ to $10.6 \%$, with a higher standard deviation $(6.0 \%)$.

These changes indicate that the participants in both groups scored better in Q2 than in Q1. Notwithstanding the evidence of significant score improvement $(p \leq 0.05)$ from Q1 to Q2 for both groups, still, the CLMoL group shows better performance than the CL group since the difference is larger (Table 4). The paired difference score for the CLMoL group is higher than the CL group, which indicates a better score obtained by the CLMoL group in Q2 with the CLMoL intervention.

Table 4. Comparison of paired differences between Q1 and Q2 scores.

\begin{tabular}{lll}
\hline Group & $\begin{array}{l}\text { Paired Differences } \\
\text { (Q1 score }- \text { Q2 score) }\end{array}$ & p-value \\
\hline CLMoL & -12.081 & $p \leq 0.05$ \\
CL & -8.579 & $p \leq 0.05$ \\
\hline
\end{tabular}

These findings suggest that the use of CLMoL teaching tools in T\&L the HACCP principles and steps of implementation may produce higher and more consistent short-term memory assessment results. In contrast, CL learning resulted in lower and diverse score attainment.

Moving on to check if the different groups of participants could still recall the principles and steps of HACCP implementation after a month of first learning it via CLMoL and CL. Although extensive research has been carried out on the short-term memory recall for the use of MoL in learning, only a few reports are attainable on its long-term effects (Ahour \& Berenji, 2015; Vindenes, de Gortari, \& Wasson, 2018; Werner-Seidler \& Dalgleish, 2016). Additionally, only minor comparative studies were conducted simultaneously for short-term and long-term memory retrieval after using MoL (Putnam, 2015; Wang \& Thomas, 2000). Additionally, the current long-term memory retrieval investigation is consistent with a review 


\section{Ml Macrothink}

paper author's suggestion that mnemotechnic intervention should focus on investigating memory retention at longer retention intervals, especially longer than 1-week (Putnam, 2015).

Figure 4 shows the marginal mean scores of Q2 (Short-term memory assessment), which participants answered immediately after the intervention, and Q3 (Long-term memory assessment) was administered after a lapse of approximately one (1) month from first learning for both groups.

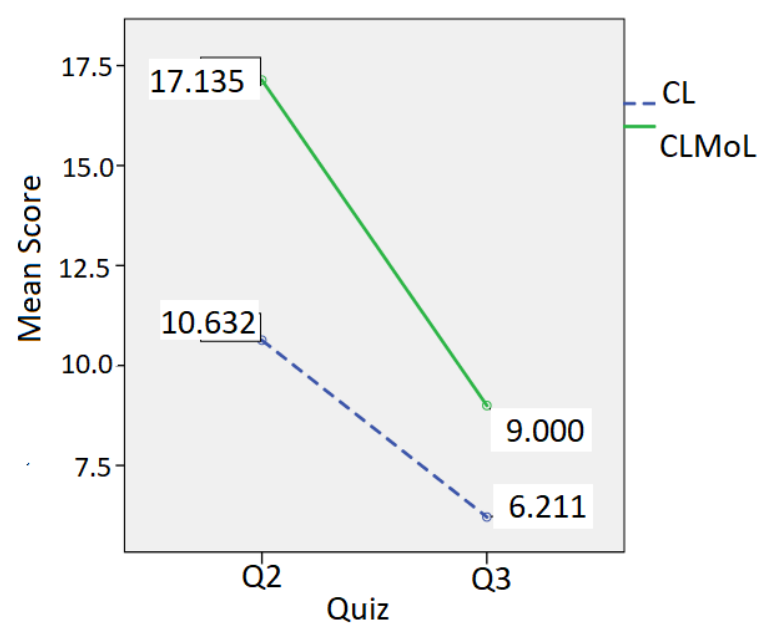

Figure 4. Marginal means score of Q2 and Q3

The mean scores for both groups indicate a declining pattern after a lapse of a month. The mean score of Q2 for the CL participants is 10.632, and for Q3 is 6.211. Whereas the mean score of Q2 for the CLMoL group is 17.135, and for Q3 is 9.000. It is apparent from Figure 4 that the mean score for the CLMoL group still surpassed the CL group. This indicates that participants from the CLMoL group scored better in both assessments compared to the CL group. This observation shows the inclusion of MoL in CL learning has helped the participants in the CLMoL group fare better in recalling the HACCP principles and steps of implementation, either with or without delayed intervals. However, both groups indicated a decline in recalling the details after a lapse of time. This long-term forgetting pattern was also reported in a serial recall study after a 2-day delay with the use of MoL (Wang \& Thomas, 2000). Nevertheless, the long-term memory performance of the CLMoL group is still significantly $(p \leq 0.05)$ better than the CL group after the use of MoL in T\&L. This result is consistent with the literature claiming that the MoL can effectively enhance recall of some information (Putnam, 2015; Vindenes et al., 2018).

In order to assess the participants' perception of CLMoL to recall the principles and the step of HACCP implementation, the participants from the CLMoL group were given an online Likert scale questionnaire with eight questions (Table 1).

The findings of the questionnaire can be compared in Figure 5a. The respondents totalling 
thirty-seven $(n=37)$ from the CLMoL group, answered the validated questionnaire immediately after Q2. The data in Figure 5a reveal that a vast of the respondents were either 'strongly agree' or 'agree' to all the eight questions (Que1-Que8) at the beginning, thus indicating that the participants were confident that the use of CLMoL teaching tools was able to help to improve their short-term memory in memorizing the HACCP principles and implementation steps.
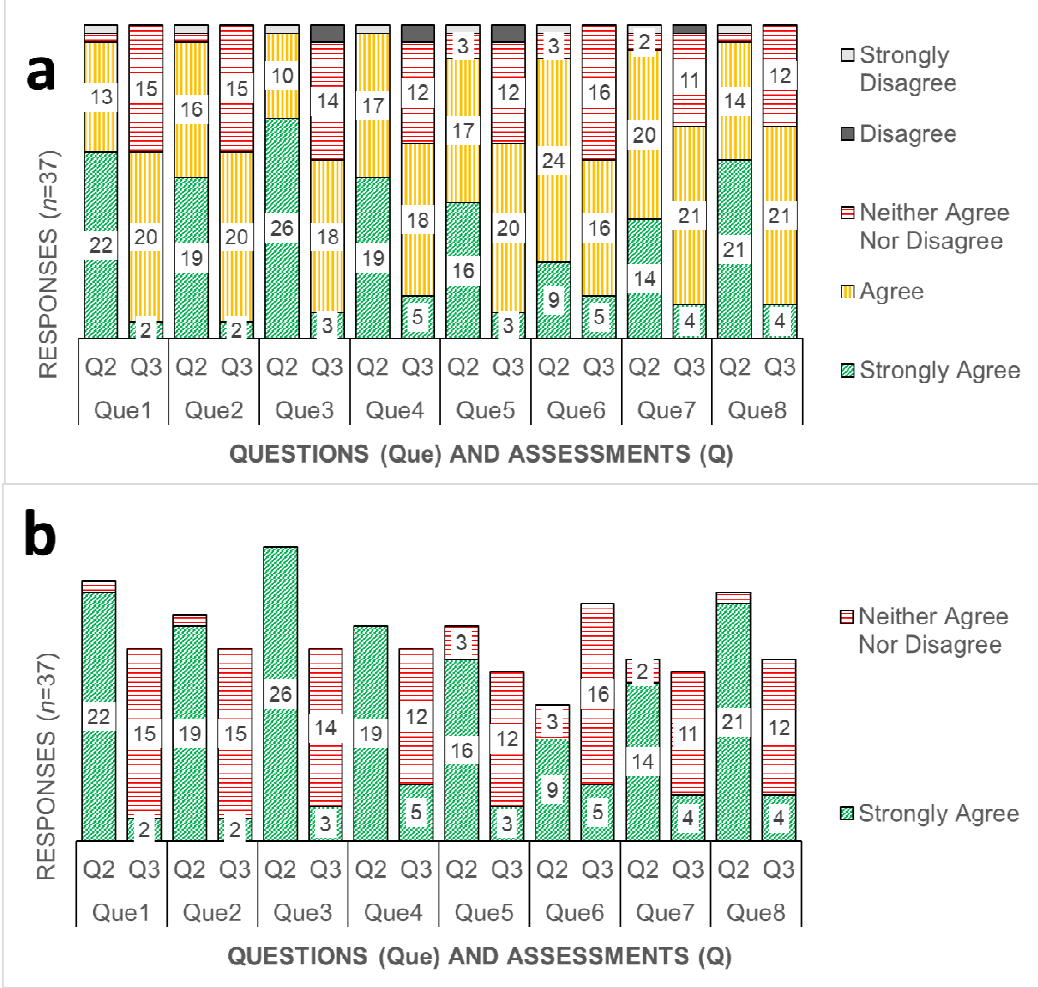

Figure 5. (a) The questionnaire responses (Question 1 (Que1) to Question 8 (Que8)) the CLMoL participants immediately after Q2 and Q3, and (b) the comparison of filtered responses (neither agree nor disagree and strongly agree) for Figure 5a

The same set of questionnaires was given immediately after taking Q3. Interestingly, the data reveal that fewer participants "strongly agree" that the use of CLMoL teaching tools was helpful for them to recall the memory after a lapse of nearly a month. The data revealed that many participants have shifted from the 'strongly agree' sector to become uncertain as they picked the "neither agree nor disagree" category in the Likert scale (Figure 5b). Thus, this indicates that they cannot decide whether CLMoL intervention helped them recall the HACCP principles and steps of implementation in answering the questions in Q3. This is a sharp contrast to participants' perception of CLMoL teaching tools after Q2, whereby their perception was strongly positive. This survey finding with respondents picking "neither agree nor disagree" was unexpected since the CLMoL participants' mean scores for Q3 reduced significantly compared to Q2 (Figure 4). Hence, interview sessions were conducted to figure 
out why the CLMoL participants did not pick "disagree" or "strongly disagree" sectors to denounce the effectiveness of CLMoL teaching tools in helping them recall their memory.

During the interview, the participants endorsed that the CLMoL teaching tools can help short-term memory recall. However, they claimed that they are struggling to retrieve their long-term memory about the HACCP principles and steps of implementation. They pointed out that they were struggling to answer the questions in the questionnaire (Table 1). For instance, in the question of "MoL is a helpful learning technique in memorizing facts" (Que2), an interviewee expressed that he did not pick "strongly disagree" after Q3 because of the use of CLMoL teaching tools does help in short-term memory. This finding suggests that the questionnaires given after Q3 should be reviewed; the same set of questionnaires may likely not be suitable to assess the long-term memory of the CLMoL participants' perception. In future investigations, it might be more applicable to use another set of modified questionnaires that can evaluate the participants' long-term memory perceptions.

Despite that, all interviewees agreed that CLMoL teaching tools were helpful for short-term memory recall in the current study. However, it is less effective for long-term memory retrieval. The interviewees disclosed that they forgot what each illustration figure stood for when they were trying to associate it with the HACCP principles and steps of implementation, making it difficult to recall the correct descriptions for the principles and steps. Further discussion during the interview sessions also discovered that the present visual illustration of the MoL (Figure 1) and its translation into the spatial syntax of the lecture room is scattered and inefficient.

The interviewees suggested that the visual illustration could be revised and enhanced. This can be done by segregating the icons in the illustration at four (4) different walls in the lecture room instead of congregating most of the icons at the front part of the lecture room. They granted credence that modifying the teaching tools may likely enhance their long-term memory recall for the HACCP principles and implementation steps. Following the present observation, it is consistent with a suggestion by a previous study that the augmented method used together with the MoL has a critical role in enhancing the subjects' memory retention for science-related vocabulary and facts (Richmond, Cummings, \& Klapp, 2008). However, the current imagined navigation of MoL based on the developed teaching tools requires better peg-based strategies to increase the effectiveness of T\&L and memory recall (Caplan, Legge, Cheng, \& Madan, 2019).

Therefore, as suggested by Qureshi, Rizvi, Syed, Shahid, and Manzoor (2014), the students should be continuously encouraged to master the MoL mnemotechnic intervention to facilitate learning in class, this may take them to the next step to exploit their newly learned skill in other chapters or subjects as well, this would keep the students abreast with MoL mnemonic technique all the time without any lapse.

\section{Conclusion}

Taken together, the use of CLMoL teaching tools has given clear indicators that it led to better short-term memory recall for the HACCP principles and steps of implementation. Even though long-term memory retrieval for the CLMoL treated participants seem still better than the $\mathrm{CL}$, the effectiveness of CLMoL teaching tools in recalling long-term memory in the 
present study is inconclusive due to the significantly lower written assessment score obtained by the CLMoL participants after a month interval. In addition, this study also demonstrated that the use of CLMoL teaching tools in T\&L may produce higher and more consistent short-term memory assessment results within the treated group than solely using CL in T\&L HACCP principles and steps of implementation. This study may be repeated using enhanced visual illustration tools by segregating the icons in the illustration at four (4) different walls in the lecture room. This may lead to better memory improvement.

\section{Acknowledgments}

The authors would like to thank the Academic Affair Divisions of Universiti Teknologi MARA Cawangan Negeri Sembilan for supplying the Cumulative Grade Point Average (CGPA) data of the participants in this study. Special thanks to all the participants from Diploma in Food Technology Program (session 1 2019/2020) at the Universiti Teknologi MARA (UiTM), Kuala Pilah Campus. The authors declare that this research was performed as part of the Universiti Teknologi MARA employment for the authors, and there is no funding from any funding agency in the public, commercial or non-profit sectors.

\section{References}

Ahour, T., \& Berenji, S. (2015). A comparative study of rehearsal and loci methods in learning vocabulary in EFL context. Theory and Practice in Language Studies, 5(7), 1451. https://doi.org/10.17507/tpls.0507.18

Allata, S., Valero, A., \& Benhadja, L. (2017). Implementation of traceability and food safety systems (HACCP) under the ISO 22000: 2005 standard in North Africa: The case study of an ice cream company in Algeria. Food Control, 79, 239-253. https://doi.org/10.1016/j.foodcont.2017.04.002

Bram, B., Sutono, A. A., \& Hermayani, T. (2020). Applying the principles of Matteo Ricci's memory palace technique. Journal of Applied Studies in Language, 4(1), 9-18. https://doi.org/10.31940/jasl.v4i1.1572

Brehmer, Y., Li, S. C., Müller, V., von Oertzen, T., \& Lindenberger, U. (2007). Memory plasticity across the life span: uncovering children's latent potential. Developmental Psychology, 43(2), 465. https://doi.org/10.31940/jasl.v4i1.1572

Brehmer, Y., Li, S. C., Straube, B., Stoll, G., Von Oertzen, T., Müller, V., \& Lindenberger, U. (2008). Comparing memory skill maintenance across the life span: Preservation in adults, increase in children. Psychology and Aging, 23(2), 227. https://doi.org/10.1037/0882-7974.23.2.227

Caplan, J. B., Legge, E. L., Cheng, B., \& Madan, C. R. (2019). Effectiveness of the method of loci is only minimally related to factors that should influence imagined navigation. Quarterly Journal of Experimental Psychology, 72(10), 2541-2553. https://doi.org/10.1177/1747021819858041

Dalgleish, T., Navrady, L., Bird, E., Hill, E., Dunn, B. D., \& Golden, A.-M. (2013). Method-of-loci as a mnemonic device to facilitate access to self-affirming personal memories 
for individuals with depression. Clinical Psychological Science, 1(2), 156-162. https://doi.org/10.1177/2167702612468111

De Beni, R., \& Cornoldi, C. (1988). Does the repeated use of loci create interference? Perceptual and Motor Skills, 67(2), 415-418. https://doi.org/10.2466/pms.1988.67.2.415

Hartwig, M. K., \& Dunlosky, J. (2012). Study strategies of college students: Are self-testing and scheduling related to achievement? Psychonomic Bulletin \& Review, 19(1), 126-134. https://doi.org/10.3758/s13423-011-0181-y

Huttner, J. P., Qian, Z., \& Robra-Bissantz, S. (2019). A virtual memory palace and the user's awareness of the method of loci. Paper presented at the 27th European Conference on Information Systems (ECIS), Stockholm \& Uppsala, Sweden. Retrieved from https://aisel.aisnet.org/ecis2019_rp/7/

Kurniarahman, I. (2020). The effect of mnemonic loci technique on students' vocabulary memorization. $\quad$ Language-Edu, 9(1). Retrieved from http://www.riset.unisma.ac.id/index.php/LANG/article/view/5094

Lu, J., Pua, X. H., Liu, C. T., Chang, C. L., \& Cheng, K. C. (2014). The implementation of HACCP management system in a chocolate ice cream plant. Journal of Food and Drug Analysis, 22(3), 391-398. https://doi.org/10.1016/j.jfda.2013.09.049

Massen, C., \& Vaterrodt-Plünnecke, B. (2006). The role of proactive interference in mnemonic techniques. Memory, 14(2), 189-196. https://doi.org/10.1016/j.jfda.2013.09.049

McCabe, J. (2011). Metacognitive awareness of learning strategies in undergraduates. Memory \& Cognition, 39(3), 462-476. https://doi.org/10.3758/s13421-010-0035-2

McCabe, J. (2015). Location, location, location! Demonstrating the mnemonic benefit of the method of loci. Teaching of Psychology, 42(2), 169-173. https://doi.org/10.1177/0098628315573143

McCabe, J. (2018). What learning strategies do academic support centers recommend to undergraduates? Journal of Applied Research in Memory and Cognition, 7(1), 143-153. https://doi.org/10.1016/j.jarmac.2017.10.002

McDaniel, M. A., \& Bugg, J. M. (2012). Memory training interventions: What has been forgotten? Journal of Applied Research in Memory and Cognition, 1(1), 45-50. https://doi.org/10.1016/j.jarmac.2011.11.002

Mortimore, S., \& Wallace, C. (2013). HACCP: A practical approach. Springer Science \& Business Media. https://doi.org/10.1007/978-1-4614-5028-3

Perrault, S. T., Lecolinet, E., Bourse, Y. P., Zhao, S., \& Guiard, Y. (2015). Physical loci: Leveraging spatial, object and semantic memory for command selection. Paper presented at the Proceedings of the 33rd annual acm conference on human factors in computing systems. https://doi.org/10.1145/2702123.2702126

Putnam, A. L. (2015). Mnemonics in education: Current research and applications. 
Translational Issues in Psychological Science, 1(2), 130. https://doi.org/10.1037/tps0000023

Qureshi, A., Rizvi, F., Syed, A., Shahid, A., \& Manzoor, H. (2014). The method of loci as a mnemonic device to facilitate learning in endocrinology leads to improvement in student performance as measured by assessments. Advances in Physiology Education, 38(2), 140-144. https://doi.org/10.1152/advan.00092.2013

Rawendy, D., Ying, Y., Arifin, Y., \& Rosalin, K. (2017). Design and development game Chinese language learning with gamification and using mnemonic method. Procedia Computer Science, 116, 61-67. https://doi.org/10.1016/j.procs.2017.10.009

Richmond, A. S., Cummings, R., \& Klapp, M. (2008). Transfer of the method of loci, pegword, and keyword mnemonics in the eighth-grade classroom. Researcher, 21(2), 1-13. Retrieved from http://www.nrmera.org/wp-content/uploads/2016/02/Researcherv21n2Richmond.pdf

Rifqie Mariana, R., Hidayati, L., \& Soekopitojo, S. (2019). Implementing the HACCP system to the production of Bakso Malang-Indonesia. Journal of Culinary Science \& Technology, 17(4), 291-312. https://doi.org/10.1080/15428052.2018.1442760

Sekaran, U., \& Bougie, R. (2016). Research methods for business: A skill building approach. John Wiley \& Sons.

Shaughnessy, T. M., \& White, M. L. (2012). Making macro memorable: The method of loci mnemonic technique in the economics classroom. Journal of Economics and Finance Education, 11(2). Retrieved from http://www.economics-finance.org/jefe/volume11-2/10.making $\% 20$ macro $\% 20$ memorable $\% 2$ $0(1) \cdot p d f$

Shaw, J., \& Hosseini, S. (2020). The Effect of Baseline Performance and Age on Cognitive Training Improvements in Older Adults: A Qualitative Review. The Journal of Prevention of Alzheimer's Disease, 1-10. https://doi.org/10.14283/jpad.2020.55

Singzon, S. (2020). Virtual memory palaces: A discursive design to improve recall in older adults. Drexel University, Pennsylvania. Retrieved from https://www.proquest.com/openview/d6645ec6d4f7216aa3461 cbe25dca4e7/1?pq-origsite=gs cholar \&cbl=18750\&diss $=\mathrm{y}$

Tan, E. T. T. (2021). Malaysia, Patent No. LY2021M00863. Copy Right: Intellectual Property Corperation of Malaysia (MyIPO).

Vetter, A., Götz, D., \& von Mammen, S. (2020). The Art of Loci: Immerse to Memorize. Paper presented at the 2020 IEEE Conference on Games (CoG). https://doi.org/10.1109/CoG47356.2020.9231610

Vindenes, J., de Gortari, A. O., \& Wasson, B. (2018). Mnemosyne: Adapting the method of loci to immersive virtual reality. Paper presented at the International Conference on Augmented Reality, Virtual Reality and Computer Graphics. https://doi.org/10.1007/978-3-319-95270-3_16 


\section{Macrothink}

International Journal of Social Science Research

ISSN 2327-5510 2022, Vol. 10, No. 1

Wang, A. Y., \& Thomas, M. H. (2000). Looking for long-term mnemonic effects on serial recall: The legacy of Simonides. The American Journal of Psychology, 113(3), 331. https://doi.org/10.2307/1423362

Werner-Seidler, A., \& Dalgleish, T. (2016). The method of loci improves longer-term retention of self-affirming memories and facilitates access to mood-repairing memories in recurrent depression. Clinical Psychological Science, 4(6), 1065-1072. https://doi.org/10.1177/2167702615626693

Wilding, J. M., \& Valentine, E. R. (1997). Superior memory. Psychology Press.

Yates, F. A. (1966). The art of memory. Chicago and London

\section{Copyrights}

Copyright for this article is retained by the author(s), with first publication rights granted to the journal.

This is an open-access article distributed under the terms and conditions of the Creative Commons Attribution license (http://creativecommons.org/licenses/by/4.0/). 